\title{
Caracterização das argamassas de revestimento históricas existentes na Usina Ilha Bela, localizada no município de Ceará Mirim, RN
}

\author{
Characterisation of the historical coating mortars in the \\ Ilha Bela Plant located in the city of Ceará Mirim, RN
}

\section{Adna Lúcia Rodrigues de Menezes Kleber Cavalcanti Cabral Antonio Eduardo Martineli}

\section{Resumo}

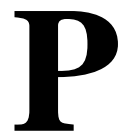

rocurando manter a identidade de uma sociedade, a busca pela conservação do patrimônio cultural é fundamental. As edificações históricas são partes integrantes deste patrimônio, pois guardam evidências sobre a história construtiva da edificação, bem como métodos e materiais, o que é de suma importância para atender aos princípios de preservação desses bens. Nesse contexto, este trabalho tem como objetivo caracterizar as argamassas de revestimento da Usina Ilha Bela, RN. Para tal, foi realizada visita in loco para observação visual e registro fotográfico da edificação, e coleta de amostras de argamassas do prédio administrativo, balança e fábrica da Usina para posterior caracterização físico-química e mineralógica por meio de análise visual e técnicas analíticas em laboratório. A partir das análises constatouse que as argamassas estudadas são ricas em cal, com aglomerante de natureza calcítica e areia de origem silicosa, como agregado, com a presença de argila. Verificou-se a existência de diferentes traços para as argamassas, cujas relações aglomerante/agregado são: 1:4 até 1:9, dependendo do prédio e do local de extração das amostras. Desse modo, a partir das informações sobre as argamassas existentes é possível projetar uma argamassa de reconstituição compatível para realização da conservação desses monumentos históricos, ressaltando seus valores.

Palavras-chave: Argamassas históricas. Conservação. Restauro.

\begin{abstract}
In order to preserve a society's identity, it is fundamental to seek the conservation of its cultural heritage. Historic buildings are an integral part of this heritage, as they contain evidence about the building's constructive history, as well as methods and materials, which are of utmost importance in order to preserve these assets. This study aims to characterise the coating mortars of the Ilha Bela, RN Plant. In order to do that, the researchers undertook on-site visits for visual observation and photographic registration of the building, and also collected mortar samples from the administrative building, scale and factory of the Plant for subsequent physical-chemical and mineralogical characterisation through visual analysis and analytical techniques in the laboratory. The analyses revealed that the mortars studied are rich in lime, with calcitic binders and siliceous sand as aggregate, with the presence of clay. The study showed the existence of different traces in the mortars, whose binder/aggregate ratios are: 1:4 to 1:9, depending on the building and sample extraction site. Hence, from the information about the existing mortars, it is possible to design a mortar of compatible constitution for the accomplishment of the conservation of these historic monuments, emphasising their values.

Keywords: Historical mortars. Conservation. Restoration.
\end{abstract}

${ }^{2,3}$ Kleber Cavalcanti Cabral 2Universidade Federal Rural do Semi-
Árido Angicos - RN - Brasil Árido Angicos - RN - Brasil ${ }^{3}$ Universidade Federal do Rio Grande
do Norte Natal - RN - Brasil

${ }^{4}$ Antonio Eduardo Martinelli ${ }^{4}$ Universidade Federal do Rio Grande do Norte Natal - RN - Brasil

Recebido em 15/01/19 Aceito em 29/09/19

MENEZES, A. L. R. de; CABRAL, K. C.; MARTINELLI, A. E. Caracterização das argamassas de revestimento históricas 


\section{Introdução}

Edificação histórica é definida como uma construção que apresenta características de grande valor arquitetônico, cultural e histórico (SOUSA, 2014). Esse conceito está ligado ao patrimônio histórico edificado, que se elege por ser um bem cultural que é produzido por um determinado povo, nação ou civilização, representando de melhor maneira seu passado (ROSA, 2016).

Compreender os edifícios históricos significa também entender e conhecer os materiais existentes desde décadas e séculos passados. As argamassas antigas que compõem esses monumentos guardam evidências acerca da história construtiva da edificação, os métodos e os materiais. Portanto, devem ser preservadas a fim de servir como parâmetro para definição de argamassas de reconstituição para manter e conservar periodicamente o edifício histórico (KANAN, 2008).

Na conservação e reabilitação de edifícios, as argamassas de revestimento desempenham um papel essencial e, devido à sua exposição e atribuição de proteger o substrato, são os primeiros elementos do edifício no qual é perceptível a degradação (DAMAS; VEIGA; FARIA, 2016).

Eram predominantes na composição dos materiais das argamassas de revestimento antigo dois componentes, o aglomerante (cal) e o agregado (areia), podendo ainda conter adições pozolânicas ou material orgânico, de acordo com a caracterização do prédio Grupo Escolar Augusto Severo em Natal, RN, de 1908 (SOUSA, 2014). No entanto, os métodos construtivos de paredes eram diferentes de uma região para outra, e, além disso, a constituição desses materiais passou por modificação ao longo dos anos (VEIGA, 2012).

Atualmente, a preocupação sucessiva em reabilitar os edifícios tem levado a tomada de decisões indevidas, geralmente resultando na remoção de argamassas antigas, com perda do seu valor, tanto técnico como estético, entre outros, e na sua substituição por argamassas novas (FARIA; HENRIQUES; RATO, 2008).

Maravelaki-Kalaitzaki et al. (2005) relatam ainda que comumente essa intervenção não obedece aos requisitos fundamentais de compatibilidade física e química com o substrato, propiciando muitas vezes um dano maior. À vista disso, pesquisas recentes enfocam o uso de materiais compatíveis com substratos originais (TAGLIERI et al., 2017).

No Brasil, o Instituto do Patrimônio Histórico e Artístico Nacional (IPHAN) é o órgão federal de preservação que se encarrega do exercício preservacionista no país. Ele foi criado em 1937, e o primeiro tombamento do Rio Grande do Norte foi realizado no ano de 1949 (INSTITUTO..., 2017). Além deste, existe no Estado a Fundação José Augusto (FJA), que também tem a finalidade de promover a restauração, conservação e manutenção de monumentos históricos e artísticos do Estado.

A lista de bens tombados por ambos, IPHAN e FJA, no Estado ainda não abrange todas as edificações históricas existentes. Pouca atenção foi dada ao vale do Ceará-Mirim, que carrega um passado de tradições de uma economia rural e patriarcal, no qual os engenhos, distribuídos no decurso do vale, desenham a paisagem açucareira da região.

A transição desse período de progresso da atividade açucareira é notável por meio da presença de patrimônio material na região. Constatam-se inúmeras construções arquitetônicas associadas a esse momento histórico no decorrer do vale, muitas delas já em ruínas (BERTRAND, 2010).

Dentre os engenhos instalados ao longo do vale do rio Ceará-Mirim, o engenho Ilha Bela se destacou por apresentar uma implantação singular. Suas atividades tiveram início entre os anos 1888 e 1889 , e posteriormente foi transformado em usina para produção de açúcar cristal.

Diante desse contexto, esta pesquisa tem como principal objetivo caracterizar as argamassas de revestimento da Usina Ilha Bela, RN, contribuindo para preservação e consolidação desses monumentos históricos, através das análises de aspecto visual, FRX, DRX, TG, teor de aglomerante, granulometria, absorção de água por imersão e resistência à compressão.

\section{Materiais e métodos}

O procedimento experimental da pesquisa compreendeu duas etapas. Primeiro foi realizada uma análise do estado de conservação da edificação, seguido da caracterização das argamassas antigas de cada prédio pertencente à Usina Ilha Bela. 


\section{Análise do estado de conservação da Usina Ilha Bela}

As práticas preservacionistas das alvenarias históricas exigem o entendimento dos materiais remanescentes dos que vão ser usados na reconstituição. Para isso, foram realizadas visitas in loco na Usina (Figuras 1 e 2) para verificar a situação atual da edificação, assim como identificar os diferentes ambientes e a possível existência de intervenções que esta possa ter recebido no decorrer dos anos.

Essa inspeção visual foi realizada atentando para as recomendações de Kanan (2008).

Foram extraídas amostras da argamassa de revestimento externo e interno de cada prédio, com o auxílio de uma talhadeira e martelo, distribuídos entre 3 prédios existentes da Usina: prédio administrativo, balança e fábrica. As amostras foram retiradas a uma altura aproximada de 1,50 $\mathrm{m}$ do nível do piso, tendo o devido cuidado de agredir o mínimo do monumento histórico.

O critério para a escolha dos pontos foi a retirada em pelo menos 3 pontos, para que se pudesse ter uma representação melhor da argamassa em cada face da edificação.

No prédio administrativo foram extraídas amostras em 3 pontos da parede frontal interna e em 3 pontos dessa mesma parede frontal na face externa, de forma a se obter uma amostra menos deteriorada. Assim como foi a extração das amostras na fábrica, em 3 pontos da parede frontal externa como também em 3 pontos dessa parede na face interna, e essas paredes escolhidas por apresentarem uma melhor conservação, comparada às demais paredes de cada prédio analisado. E no prédio onde funcionava a Balança $\left(1^{\circ}\right.$ andar $)$ foram extraídas amostras em 3 pontos distribuídos nas parede laterais internas que estavam menos degradadas e em 3 pontos da parede lateral esquerda externa, considerando 1,50 $\mathrm{m}$ do piso do $1^{\circ}$ andar, sendo essa a única parede praticável de extração de amostra, uma vez que as demais paredes não tinham acesso para alcançar essa altura de extração estabelecida.

Em seguida, os materiais coletados foram armazenados em recipientes plásticos, limpos e secos e identificados individualmente. Como parte da observação visual, as amostras foram fotografadas, mostrando seções importantes para análise quanto a cor, textura, espessura e resistência (compacta ou quebradiça). O Quadro 1 ilustra a identificação, o substrato e o local de retirada de cada amostra.

Figura 1 - (a) Usina Ilha Bela e (b) Prédio administrativo da Usina

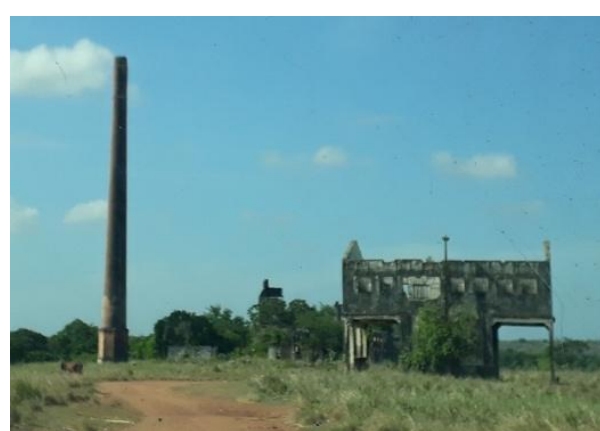

(a)

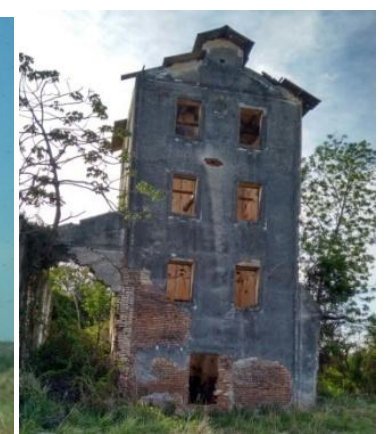

(b)

Figura 2 - (a) Fábrica da Usina e (b) Balança da Usina

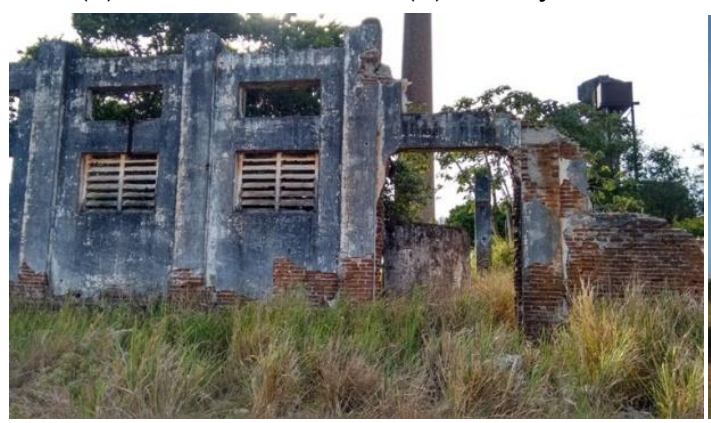

(a)

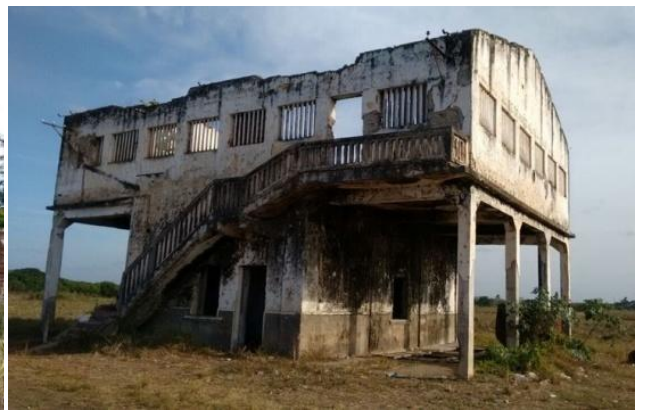

(b) 
Quadro 1 - Nomenclatura, substrato e local de extração das amostras da Usina

\begin{tabular}{|c|c|c|c|}
\hline \multicolumn{2}{|c|}{ Nomenclatura das amostras } & Substrato & \multirow{2}{*}{ Local de extração } \\
\hline A01 & Revestimento externo & Parede - tijolo de adobe & \multirow{2}{*}{ Prédio administrativo } \\
\hline A02 & Revestimento interno & Parede - tijolo de adobe & \multirow{2}{*}{ Balança } \\
\hline A03 & Revestimento externo & Parede - tijolo de adobe & \multirow{2}{*}{ Fábrica } \\
\hline A04 & Revestimento interno & Parede - tijolo de adobe & \\
\hline A05 & Revestimento externo & Parede - tijolo de adobe & \multirow{2}{*}{ A06 } \\
\hline
\end{tabular}

\section{Caracterização das argamassas antigas da Usina Ilha Bela}

Após a coleta das amostras, para conhecer as características físicas e químicas da argamassa antiga foram realizadas técnicas de caracterização dos materiais. As técnicas de caracterização adotadas foram baseadas em trabalhos anteriores, dentre eles (DAMAS et al., 2018; ORTEGA et al., 2018; DAMAS; VEIGA; FARIA, 2016; HORMES et al., 2016; LEZZERINI et al., 2018, 2014; SOUSA, 2014; BARTZ et al., 2012; GLEIZE et al., 2009; LANAS et al., 2004).

Dessa maneira, para análise mais complexa das argamassas de revestimento da Usina, foram realizadas as seguintes técnicas:

(a) fluorescência de raios $\mathrm{X}(\mathrm{FRX})$;

(b) difração de raios X (DRX);

(c) análise termogravimétrica (TG);

(d) teor de aglomerante e agregado;

(e) distribuição granulométrica após o ataque ácido;

(f) absorção de água por imersão; e

(g) resistência à compressão.

Para isso, parte da amostra foi desagregada cautelosamente com um almofariz de porcelana e um martelo de borracha. Posteriormente, uma porção do material foi destorroada até atingir uma fração mais fina, e então passar na peneira $\emptyset=0,075 \mathrm{~mm}$ (\#200). O material passante foi acondicionado em eppendorfs para serem encaminhados para análises de caracterização. A outra parte restante da amostra foi separada para determinação do teor de aglomerante.

\section{Técnicas de caracterização}

\section{Análises químicas e microestruturais}

As análises químicas e microestruturais desenvolvidas nas amostras de argamassas antigas da Usina estão apresentadas no Quadro 2.

Outra análise realizada, além dessas supracitadas, foi a determinação do teor de aglomerante. Como não exista um método-padrão para medir o teor de aglomerante, e posteriormente encontrar a relação aglomerante:agregado das argamassas históricas, foi feita uma adaptação de uma técnica combinada de tratamento térmico com dissolução em ácido clorídrico, que promove a separação do ligante dos agregados siliciosos. Técnica esta utilizada por Damas et al. (2018), Kanan (2008) e Motta (2004), em suas pesquisas.

Para seu desenvolvimento, a amostra utilizada foi destorroada sem passar pelo processo de peneiramento, seguindo as etapas:

(a) secagem de 50 gramas da amostra de argamassa antiga, em estufa a $(105 \pm 5){ }^{\circ} \mathrm{C}$, durante 24 horas;

(b) registrou-se o peso da amostra $\left(m_{!}\right)$depois de retirada da estufa e depositou o material em um béquer;

(c) em seguida, adicionou-se $150 \mathrm{ml}$ de ácido clorídrico, procedendo com agitação, e logo após a amostra ficou em repouso durante 24 horas para ocorrer a diluição total da amostra;

(d) na sequência drenou-se a solução ácida em um funil com papel-filtro para aferição dos finos inertes, e posteriormente foi lavada com água deionizada, sendo a massa do papel filtro seco aferida previamente $\left(m_{!}\right)$; 
(e) posteriormente secou-se o filtro de papel drenante com o resultante da ação térmica combinada com dissolução de ácido clorídrico, em estufa a uma temperatura de $(105 \pm 5){ }^{\circ} \mathrm{C}$, por 24 horas; e

(f) ao final aferiu-se a massa dos filtros drenantes para encontrar a quantidade de agregados $\left(m_{!}\right)$, e assim

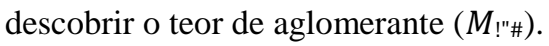

A Figura 3 apresenta a amostra de argamassa antiga com o ácido clorídrico após o repouso por 24 horas, conforme procedimento descrito anteriormente.

\section{Quadro 2 - Análises químicas e microestruturais realizadas nas amostras de argamassa}

\begin{tabular}{|c|c|c|}
\hline $\begin{array}{c}\text { Analises químicas e } \\
\text { microestruturais }\end{array}$ & Finalidade & Condições de ensaio \\
\hline $\begin{array}{l}\text { Fluorescência de raios } X \\
(\text { FRX) }\end{array}$ & $\begin{array}{l}\text { Essa análise identifica } \\
\text { qualitativamente e } \\
\text { quantitativamente os } \\
\text { elementos químicos em forma } \\
\text { de óxidos }\end{array}$ & $\begin{array}{l}\text { Essa análise é desenvolvida por } \\
\text { fluorescência de raios X utilizando o } \\
\text { espectrômetro por fluorescência de raios } \\
\text { X do tipo EDX - 720, Shimadzu, em } \\
\text { uma atmosfera a vácuo e desenvolvido o } \\
\text { método semi-quantitativo para a } \\
\text { determinação dos elementos presentes } \\
\text { nas matérias-primas }\end{array}$ \\
\hline $\begin{array}{l}\text { Difração de raios X } \\
(\text { DRX) }\end{array}$ & $\begin{array}{l}\text { Essa técnica determina a } \\
\text { composição mineralógica da } \\
\text { argamassa, ou seja, natureza } \\
\text { do agregado e aglomerante } \\
\text { que foi utilizado na argamassa } \\
\text { antiga }\end{array}$ & $\begin{array}{l}\text { O aparelho utilizado foi o equipamento } \\
\text { Shimadzu DRX - } 7000 \text { com fonte de } \\
\text { radiação } \mathrm{Cu}-\mathrm{K} \alpha \text {, tensão de } 40 \mathrm{kV} \text {, } \\
\text { corrente de filamento } 30 \mathrm{~mA} \text { e filtro } \\
\text { monocromador de níquel, com } \\
\text { velocidade de varreduras com } 5 \% \text { min e } \\
\text { leitura nos intervalos de varrimento } 10^{\circ}< \\
2 \theta<80^{\circ}\end{array}$ \\
\hline $\begin{array}{l}\text { Análise } \\
\text { termogravimétrica } \\
\text { (TGA) }\end{array}$ & $\begin{array}{l}\text { Obtém-se a curva TGA, e a } \\
\text { partir dela a DTG, que permite } \\
\text { detectar as temperaturas em } \\
\text { que acontecem as reações que } \\
\text { causam as mudanças de } \\
\text { massa, ou seja, picos de } \\
\text { desidratação e decomposição } \\
\text { dos compostos }\end{array}$ & $\begin{array}{l}\text { Utilizou-se o equipamento STA449 F3, } \\
\text { de marca Netzsch, onde a amostra foi } \\
\text { condicionada em um cadinho de } \\
\text { alumínio e adotada as seguintes } \\
\text { condições: atmosfera de nitrogênio com } \\
\text { fluxo de } 87 \mathrm{~mL} / \mathrm{min} \text { e taxa de } \\
\text { aquecimento de } 10^{\circ} \mathrm{C} / \mathrm{min} \text { com intervalo } \\
\text { de aquecimento de } 30 \text { a } 900^{\circ} \mathrm{C}\end{array}$ \\
\hline
\end{tabular}

Figura 3 - Amostra com ácido clorídrico após repouso por 24 horas

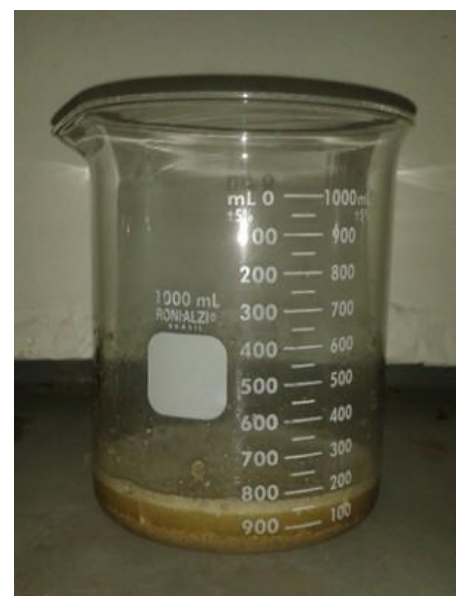


Dessa forma, o teor de aglomerante foi calculado utilizando-se a Equação 1:

$M_{a g l}=\frac{m_{1}-\left(m_{3}-m_{2}\right)}{m_{1}} x 100$

Onde:

$M_{a g l}$ : teor de aglomerante (\%);

$m_{1}$ : massa inicial da amostra $(\mathrm{g})$;

$m_{2}$ : massa do filtro drenante $(\mathrm{g})$;

$m_{3}$ : massa de agregados após ação térmica e ataque químico $(\mathrm{g})$.

Esse procedimento foi replicado para 3 amostras de cada exemplar de argamassa da Usina para se obter uma média. Após finalizar o ensaio, o material restante da dissolução em ataque ácido foi retirado do filtro cautelosamente e reservado em recipiente para ser utilizado posteriormente na análise granulométrica.

\section{Ensaios físicos}

Para determinação das caracteristicas fisicas foram realizados os seguintes ensaios:

\section{Análise granulométrica após o ataque ácido}

A análise foi realizada na amostra de argamassa após a separação do aglomerante pela técnica de determinação do aglomerante por ataque ácido. O procedimento do ensaio foi uma adaptação do que é descrito pela NBR 248 (ABNT, 2003), uma vez que a quantidade de amostra utilizada para o ensaio foi bem menor que a exigida, por se tratar de uma argamassa antiga pertencente a um edifício histórico e evitar a sua degradação. Para isso, o agregado resultante do ataque ácido e após lavagem foi seco em estufa, destorroado e depositado em um conjunto de peneiras dispostas na seguinte ordem (Tabela 1).

Através do peneiramento foi determinada a composição granulométrica do agregado utilizado nas argamassas antiga da Usina e representado em forma de curva. Essa curva granulométrica possibilita a determinação das características físicas do agregado, como o módulo de finura e diâmetro máximo, permitindo assim uma compatibilidade percentual dos diâmetros dos grãos da argamassa antiga com uma argamassa de restauro. O módulo de finura (Mf) do agregado indica a espessura deste, ou seja, quanto menor o valor do Mf, mais fino será o agregado. A partir do Mf é possível identificar em qual zona se encontra esse agregado e assim classificá-lo, conforme a NBR 7211 (ABNT, 2009).

\section{Análises absorção de água por imersão}

Para a realização desse ensaio foi necessário realizar uma adaptação da norma NBR 9778 (ABNT, 2005), já que as amostras coletadas não apresentavam o volume mínimo indicado por norma. Então, o ensaio foi realizado utilizando-se as amostras disponíveis, ilustradas na Figura 4a, e seguiu-se a metodologia de execução do ensaio apresentada na norma.

Para cada exemplar foram separadas três amostras e colocadas em estufa à temperatura de $105 \pm 5{ }^{\circ} \mathrm{C}$ por um período de $72 \mathrm{~h}$, para que após o resfriamento fosse possível determinar a massa das amostras seca (A). Em seguida, procedeu-se à imersão das amostras em água à temperatura de $23 \pm 2{ }^{\circ} \mathrm{C}$, durante $72 \mathrm{~h}$, como ilustra a Figura 4b.

\section{Tabela 1 - Conjuntos de peneiras utilizado no ensaio de granulometria}

\begin{tabular}{c|c}
\hline Conjunto de peneiras & Abertura da malha \\
\hline $\mathrm{N}^{\circ} 4$ & $4,75 \mathrm{~mm}$ \\
$\mathrm{~N}^{\circ} 8$ & $2,36 \mathrm{~mm}$ \\
$\mathrm{~N}^{\circ} 16$ & $1,18 \mathrm{~mm}$ \\
$\mathrm{~N}^{\circ} 30$ & $0,600 \mathrm{~mm}$ \\
$\mathrm{~N}^{\circ} 50$ & $0,300 \mathrm{~mm}$ \\
$\mathrm{~N}^{\circ} 1000$ & $0,150 \mathrm{~mm}$ \\
$\mathrm{~N}^{\circ} 2000$ & $0,075 \mathrm{~mm}$ \\
\hline
\end{tabular}


Figura 4 - (a) Amostras para ensaio de absorção de água; e (b) Amostras em imersão de água por 72 horas

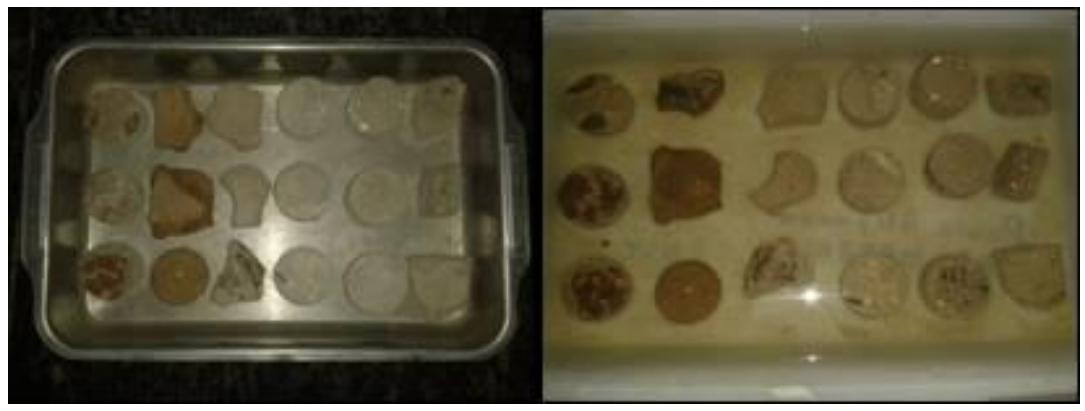

(a)

(b)

Por fim, enxugou-se a superfície das amostras e determinou-se a massa B (massa da amostra saturada em água). A partir da obtenção desses valores, calculou-se o valor de absorção de água. E foi feita a média desses valores para cada exemplar de argamassa.

\section{Resistência à compressão}

A resistência à compressão das argamassas foi determinada em corpos de prova adaptados, conforme procedimento descrito na norma NBR 5739 (ABNT, 2007).

Procedeu-se primeiramente ao preparo dos corpos de prova através de uma adequação nas amostras coletadas, por meio de uma serra-copo diamantada com $460 \mathrm{~mm}$ de diâmetro para obtenção de corpos de prova padronizados, como ilustra a Figura 5.

Após obtenção dos corpos de prova em formato-padrão, estes foram retificados e capeados com enxofre para fazer um ajuste de nivelação em suas extremidades, como mostra a Figura 6(a). Feito isso, os corpos de prova foram posicionados sobre os dispositivos de apoio do equipamento, como mostra a Figura 6(b), e uma carga com velocidade de $0,25 \mathrm{MPa} / \mathrm{s}$ foi aplicada até a ruptura do corpo de prova. Esse procedimento foi triplicado para cada exemplar de argamassa em estudo da Usina para se obter uma média do valor de resistência à compressão de cada exemplar de argamassa antiga.

Como a relação h/d (altura/diâmetro) desses corpos de prova é menor que 1,94, a NBR 5739 (ABNT, 2007) recomenda que se multiplique o valor de $f_{c}$ obtido por um fator de correção estabelecido por norma. Esse fator de correção varia conforme a relação $\mathrm{h} / \mathrm{d}$ dos corpos de prova ensaiados. Como a relação $\mathrm{h} / \mathrm{d}$ dos corpos de prova em análise estão fora dos valores estipulados na norma, foi necessário encontrar o fator de correção através da extrapolação polinomial, como mostra a Figura 7.

A Tabela 2 apresenta os fatores de correção para cada relação h/d e amostra de argamassa. A partir desses valores, foi permissível a obtenção dos valores de resistência à compressão.

\section{Resultados e discussões}

\section{Caracterização das argamassas antigas da Usina Ilha Bela}

\section{Fluorescência de raios-X}

Os resultados da fluorescência de raios-X (FRX) das amostras são apresentados na Tabela 3.

As argamassas em sua totalidade apresentaram na análise de FRX o cálcio como elemento em maior quantidade, seguido da sílica e do ferro. O alto teor de cálcio aponta, de acordo com Yaseen et al. (2013), que as argamassas coletadas na Usina Ilha Bela são ricas em cal. E o teor elevado de sílica indica a presença de areia como agregado silicioso, que foi constatada diante a desagregação do material.

As argamassas A01, A03, A04, A05 e A06 apresentaram em seus resultados de FRX maior porcentagem de cálcio, seguido de sílica e ferro. Essas amostras apresentaram ainda magnésio, alumínio, potássio, zircônio, estrôncio, manganês, titânio (exceto para a amostra A05) e zinco (exceto para as amostras A03 e A04), o que sinaliza provavelmente a presença de argila nessas argamassas.

A amostra A02 foi a argamassa que teve maior divergência das demais, pois não apresentou magnésio e alumínio em seu resultado de FRX, e depois da cal o próximo elemento em maior quantidade é o ferro. Essa 
expressiva porcentagem de ferro indica a presença do composto hematita, como será apresentado nos resultados de DRX, e explica a particularidade da cor mais escura dessa amostra quando comparada às demais, visto que, conforme Tavares (2009) e Veiga e Velosa (2008), a hematita confere as argamassas a cor vermelha.

Figura 5 - (a) Equipamento para obtenção de corpos de prova da argamassa; e (b) Corpos de prova das argamassas

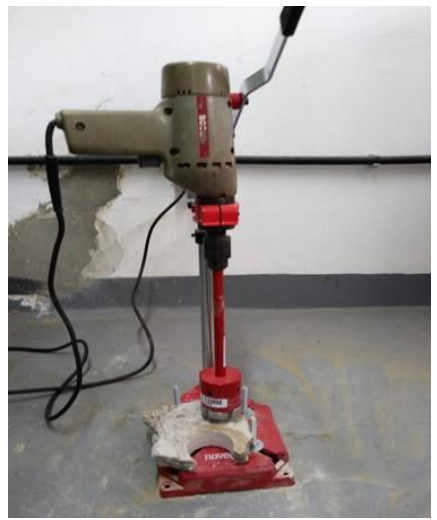

(a)

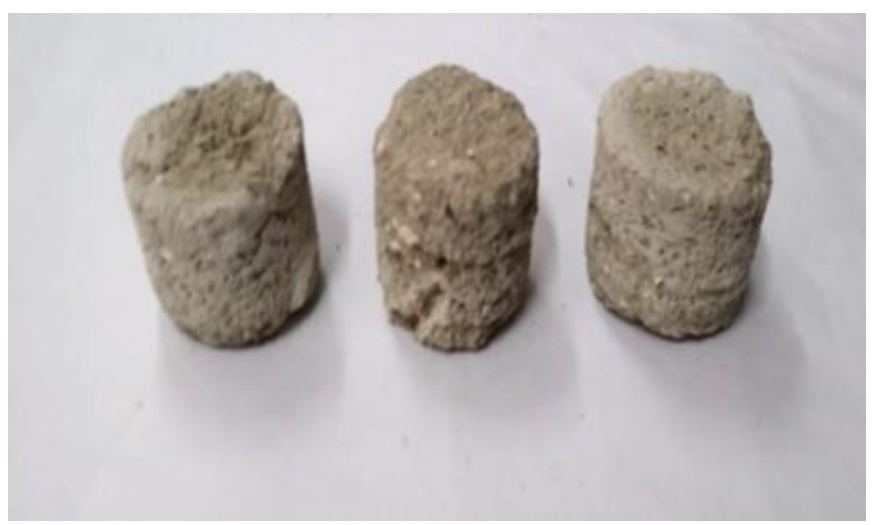

(b)

Figura 6 - (a) Corpo de prova das argamassas retificado; e (b) Corpos de prova sendo ensaiado

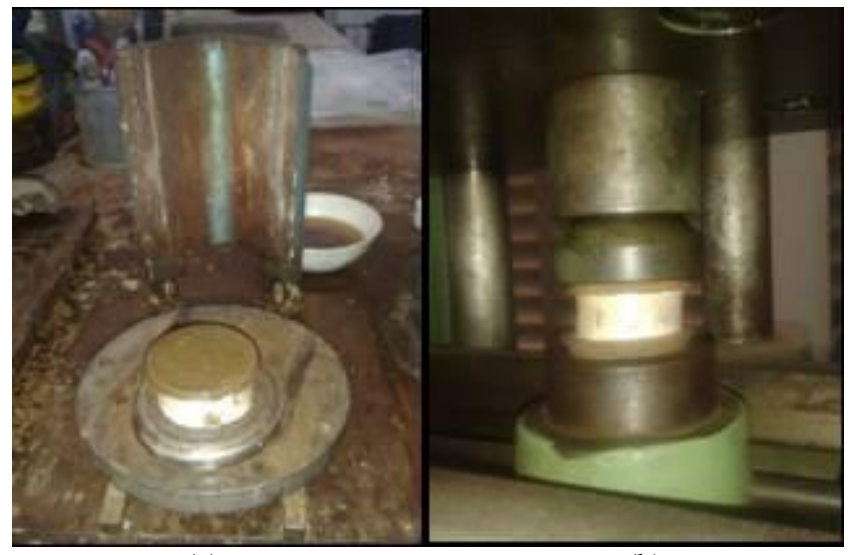

(a)

(b)

Figura 7 - Polinômio do fator de correção e relação h/d

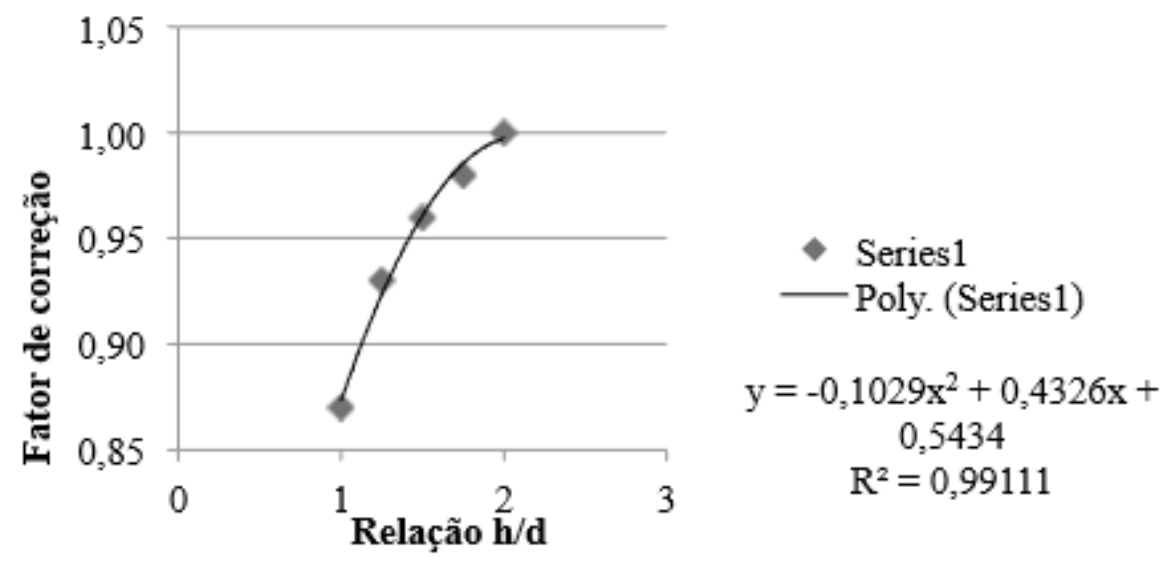


Tabela 2 - Dados para o cálculo de resistência à compressão das argamassas da Usina

\begin{tabular}{c|c|l}
\hline $\begin{array}{c}\text { Amostras de } \\
\text { argamassas da Usina }\end{array}$ & lação h/d & $\begin{array}{l}\text { Fator de } \\
\text { correção }\end{array}$ \\
\hline A01 & 0,638 & 0,778 \\
A02 & 0,630 & 0,775 \\
A03 & 0,663 & 0,785 \\
A04 & 0,826 & 0,831 \\
A05 & 0,899 & 0,849 \\
A06 & 0,652 & 0,782 \\
\hline
\end{tabular}

Tabela 3 - FRX das argamassas da Usina

\begin{tabular}{c|c|c|c|c|c|c}
\hline Elementos & $\mathbf{A 0 1}(\%)$ & $\mathbf{A 0 2}(\%)$ & $\mathbf{A 0 3}(\%)$ & $\mathbf{A 0 4}(\%)$ & $\mathbf{A 0 5}(\%)$ & $\mathbf{A 0 6}(\%)$ \\
\hline $\mathrm{CaO}$ & 66,671 & 66,220 & 65,656 & 73,617 & 63,449 & 59,427 \\
$\mathrm{SiO}_{2}$ & 14,379 & 12,295 & 13,621 & 10,928 & 15,459 & 14,575 \\
$\mathrm{Fe}_{2} \mathrm{O}_{3}$ & 7,018 & 13,921 & 6,165 & 5,335 & 7,531 & 6,446 \\
$\mathrm{MgO}$ & 3,419 & - & 3,528 & 2,858 & 1,575 & 5,416 \\
$\mathrm{Al}_{2} \mathrm{O}_{3}$ & 2,650 & - & 4,690 & 2,214 & 3,679 & 3,911 \\
$\mathrm{~K}_{2} \mathrm{O}$ & 1,691 & 3,531 & 1,500 & 1,968 & 3,001 & 2,635 \\
$\mathrm{ZrO}_{2}$ & 1,344 & 1,594 & 2,567 & 1,402 & 4,206 & 4,806 \\
$\mathrm{TiO}_{2}$ & 0,977 & 1,671 & 1,403 & 0,916 & - & 1,412 \\
$\mathrm{SO}_{2}$ & 0,829 & - & - & - & - & - \\
$\mathrm{SrO}$ & 0,41 & 0,408 & 0,621 & 0,695 & 0,914 & 0,885 \\
$\mathrm{Y}_{2} \mathrm{O}_{3}$ & - & - & 0,166 & - & - & 0,193 \\
$\mathrm{CuO}$ & - & - & - & - & - & 0,087 \\
$\mathrm{MnO}$ & 0,081 & 0,287 & 0,084 & 0,065 & 0,135 & 0,131 \\
$\mathrm{ZnO}$ & 0,441 & 0,074 & - & - & 0,051 & 0,079 \\
\hline
\end{tabular}

Portanto, a análise da composição química das argamassas utilizando o FRX revela que a cal e a sílica são os principais constituintes dessas argamassas, e que estas têm como estrutura a cal e um agregado silicioso, de acordo com Damas et al. (2018) e Bartz et al. (2012). Esses elementos constituintes também foram encontrados por Sousa (2014) em argamassas antigas de um prédio existente em região circunvizinha e do mesmo período de construção da Usina Ilha Bela.

\section{Difração de raios-X}

A análise dos difratogramas (DRX) das argamassas estão representados nas Figuras 8 a 10. Foi permissível identificar em todas as argamassas o carbonato de cálcio de natureza calcita (C) e sílica na forma de quartzo (Q).

Como se pode observar, as composições mineralógicas identificadas em todas as argamassas são coerentes e adicionais aos resultados da análise de FRX de cada amostra, apresentados na Tabela 3.

O difratograma das argamassas (A01, A03, A04, A05 e A06) apresentaram resultados semelhantes, corroborando com o FRX destas. Os picos predominantes detectados correspondem ao quartzo (Q), à calcita

(C) e, em menor intensidade, anortita (A) e caulinita (K), com exceção da A06. A caulinita, de acordo com Damas et al. (2018), pode ser confirmada pelo uso de areia não lavada na composição da argamassa, e, consoante Sousa (2014), indica a presença de argila na argamassa, o que certifica a conformidade dos elementos encontrados nos resultados de FRX dessas amostras. E a existência de anortita pode ser explicada devido à presença de cálcio e magnésio (ARAÚJO, 2017). Segundo Lavat, Trezza e Poggi (2009), a anortita é um produto resultante da calcinação de argilas bentoníticas, usadas como matérias-primas na presença de calcita.

Já no resultado do difratograma da argamassa A02 é identificado o surgimento de hematita (H), além dos picos predominantes correspondentes ao quartzo (Q), à calcita $(\mathrm{C}) . \mathrm{O}$ aparecimento desse composto hematita ratifica a existência da intensa quantidade de ferro nessa amostra e sua peculiar coloração, como já citado em seu resultado de FRX, tornando-a diferente das demais amostras de argamassa da Usina. 
Portanto, os resultados de DRX indicaram que a calcita é o principal componente de todas as amostras de argamassas constantes na Usina, sendo ligante, e que o quartzo está presente nos agregados, composição mineralógica essa já encontrada em outros exemplares de argamassas antigas, entre eles por Lezzerini et al. (2018, 2014); Damas et al. (2018); Hormes et al. (2016); Sousa (2014); Bartz et al. (2012); Gleize et al. (2009). Há presença, ainda, em algumas amostras de argilominerais como a caulinita (DAMAS et al. 2018), de caulinita e anortita (GLEIZE et al., 2009).

Figura 8 - (a) Difratograma das amostras de argamassa de revestimento externo - A01 (a) e interno A02 (b) do prédio administrativo
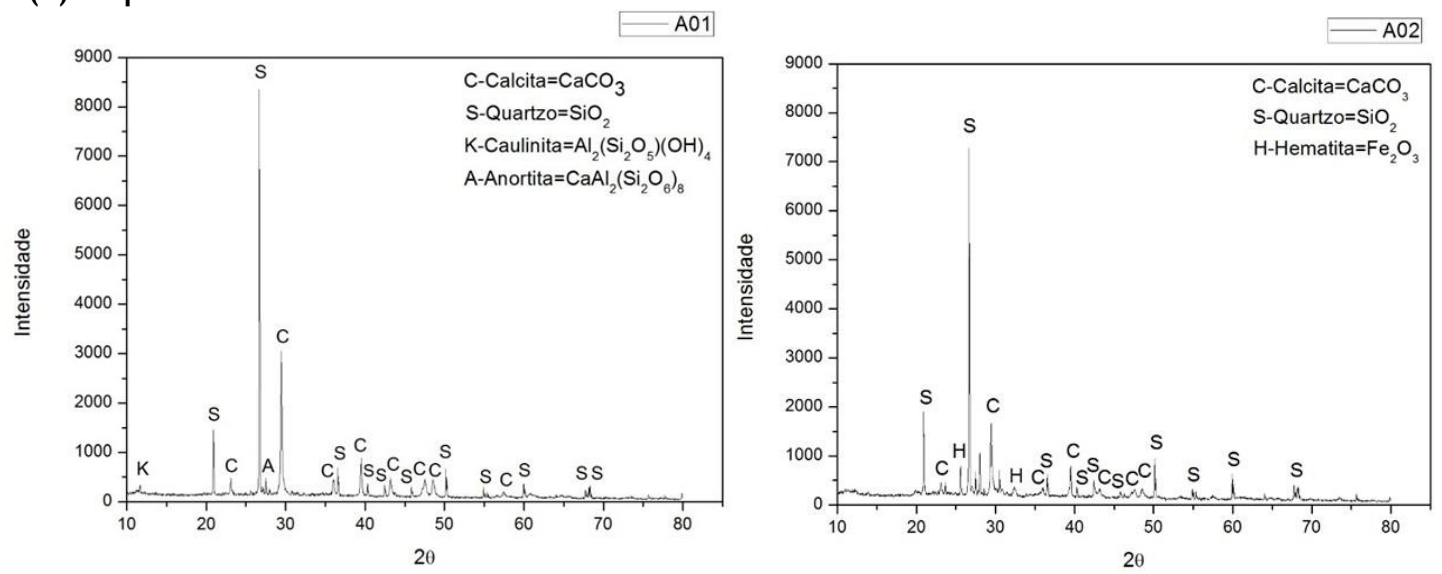

Figura 9 - (a) Difratograma das amostras de argamassa de revestimento externo - A03 (a) e interno A04 (b) da balança
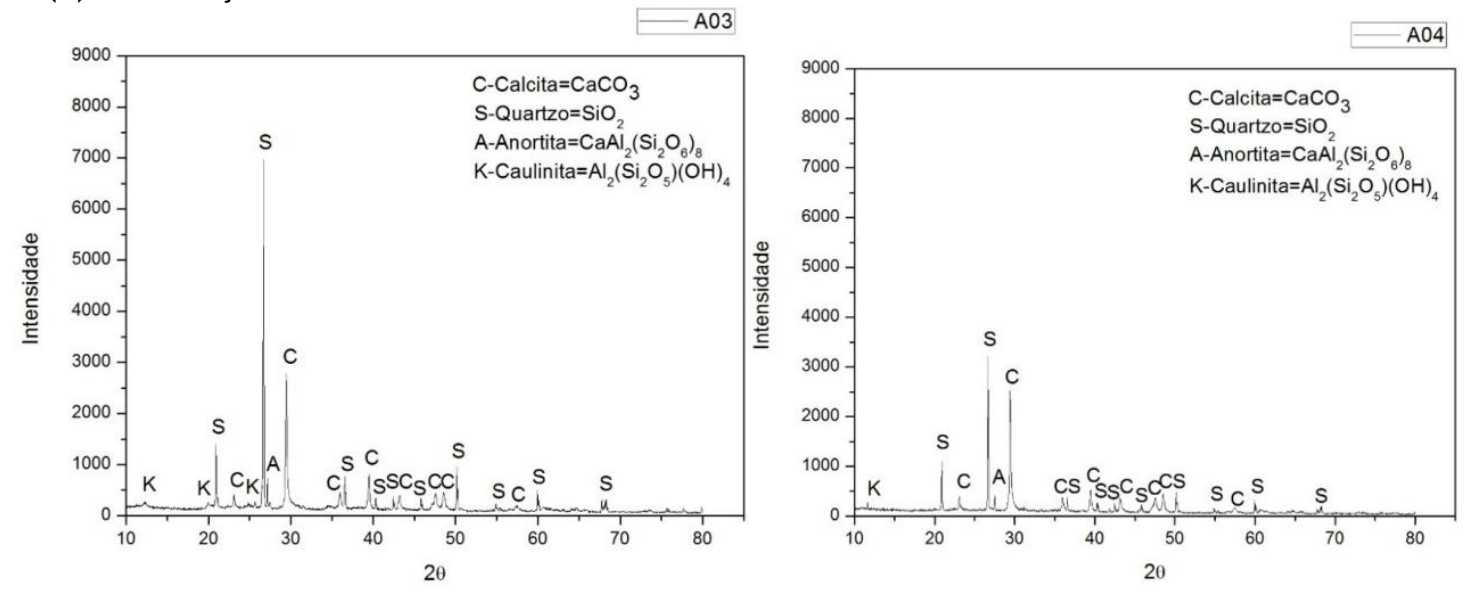

Figura 10 - (a) Difratograma das amostras de argamassa de revestimento externo - A05 (a) e interno A06 (b) da fábrica
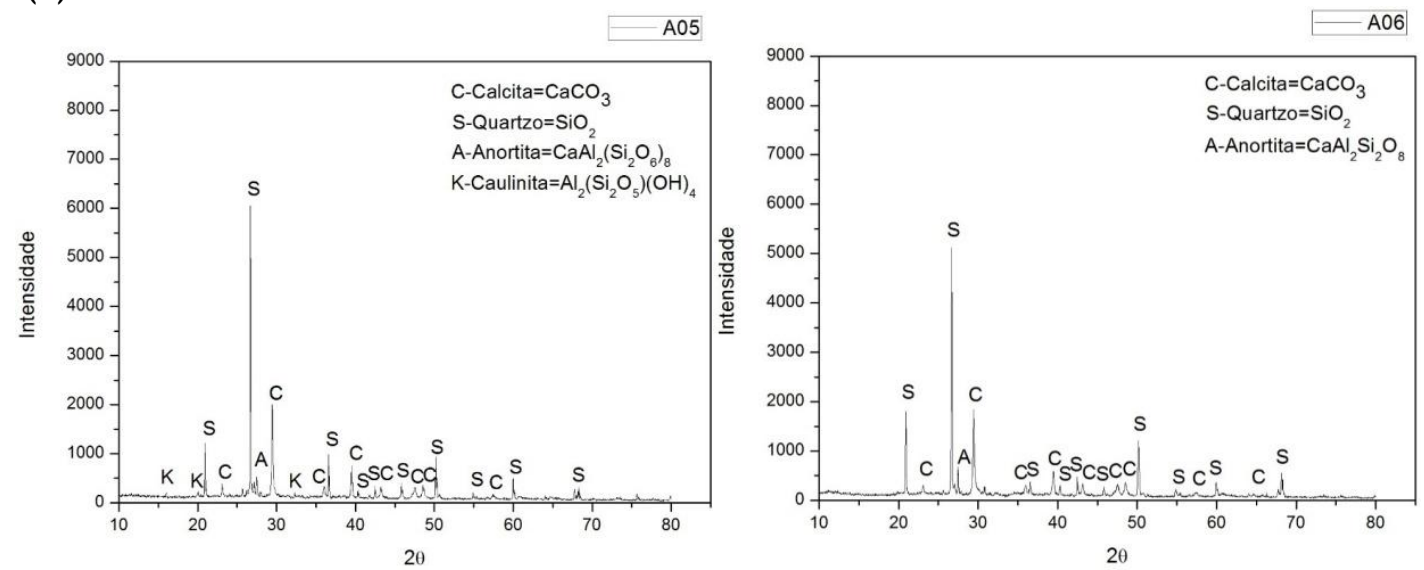


\section{Análise visual das amostras}

A seguir são apresentados os registros fotográficos nas Figuras 11 a 13 e o resultado da observação visual das argamassas coletadas na Usina Ilha Bela.

A Tabela 4 sintetiza os principais aspectos constatados nas amostras de argamassas da Usina.

Foi observado que as amostras A01 e A04 são semelhantes na cor e nas características visíveis, apresentam pontos pretos e prováveis nódulos de carbonato de cálcio e são compactas e resistente, no entanto são diferentes na espessura. Observa-se uma semelhança também nas amostras A02 e A03 quanto à espessura, aspecto pouco resistente e a provável presença de pequenos nódulos de carbonato de cálcio, porém na cor elas se divergem. A amostra A02 é a única que apresenta uma coloração diferente das demais, de castanho claro, justificando a presença de argila (barro) nessa argamassa, como será apresentado em seu resultado de FRX e DRX. E as amostras A05 e A06 são semelhantes na cor, espessura e aspectos característicos visíveis.

Esses possíveis nódulos de carbonato de cálcio visíveis nas amostras indicam, de acordo com Yaseen et al. (2013), que a cal não sofreu hidratação completa, isto é, sua hidratação foi com uma quantidade mínima de água, ou pode estar relacionado ainda a má mistura da massa de cal ou a uma reprecipitação do carbonato de cálcio, de acordo com Veiga (2017). E os pontos pretos visíveis são justificados como resíduos de carvão oriundo do processo de fabricação da cal que podem ter sido incorporados na argamassa, conforme Sousa (2014).

Figura 11 - Aspecto visual das amostras de argamassa de revestimento externo - A01 (a) e interno - A02 (b) do prédio administrativo

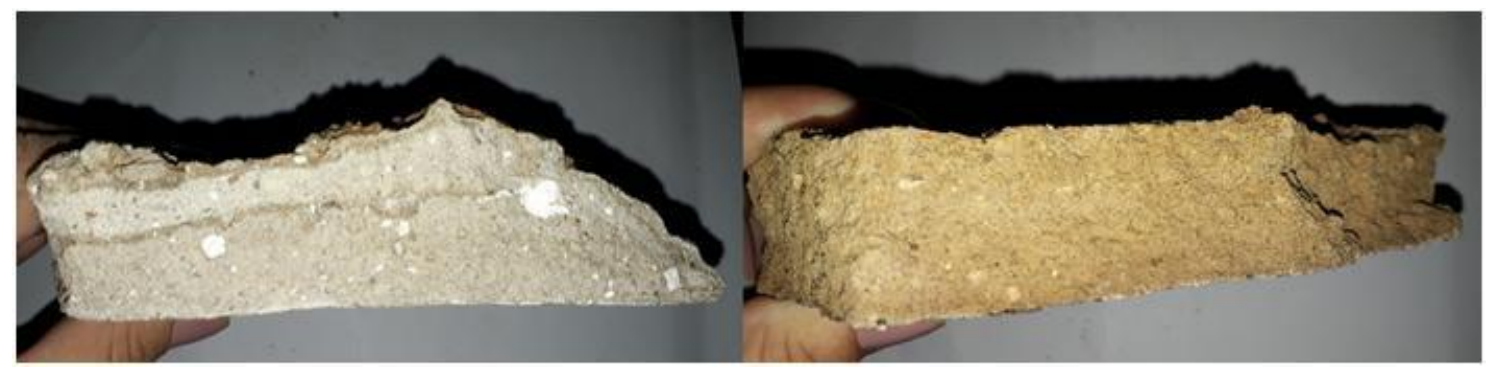

(a)

(b)

Figura 12 - Aspecto visual das amostras de argamassa de revestimento externo - A03 (a) e interno - A04 (b) da balança

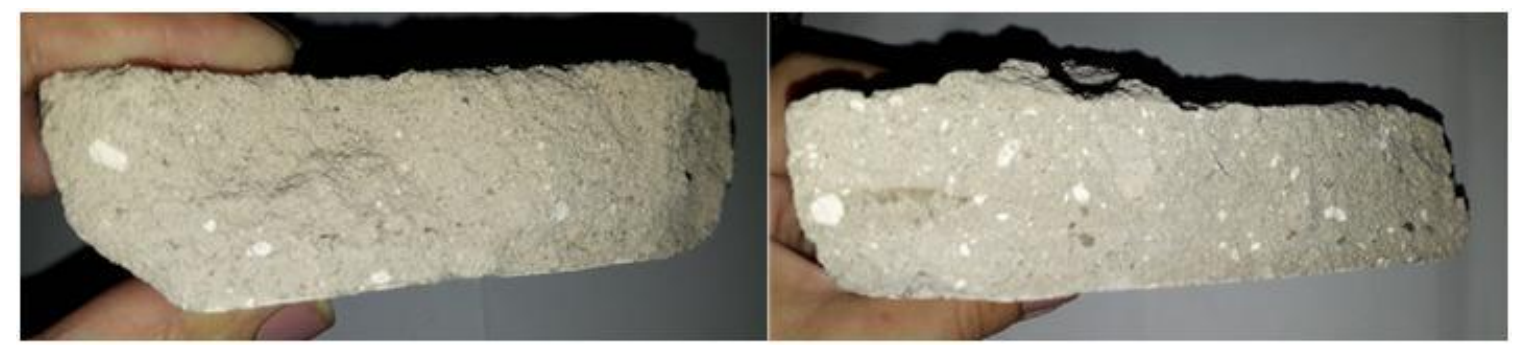

Figura 13 - Aspecto visual das amostras de argamassa de revestimento externo - A05 (a) e interno - A06 (b) da fábrica

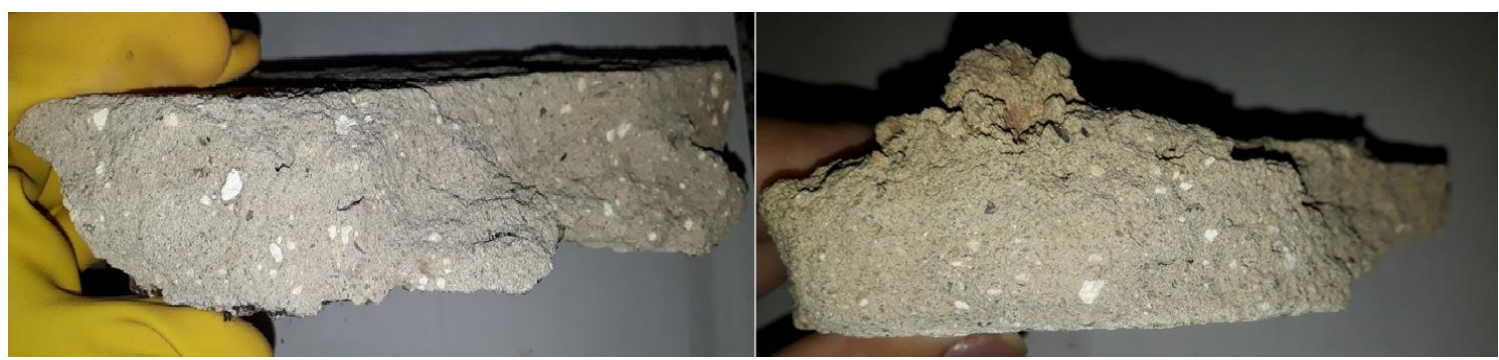


Tabela 4 - Descrição dos principais aspectos constatados na análise visual de cada amostra de argamassa da Usina

\begin{tabular}{c|c|c|c}
\hline Amostras & Cor & $\begin{array}{c}\text { Espessura } \\
\text { média }(\mathbf{c m})\end{array}$ & Outros aspectos \\
\hline A01 & Clara & 2,6 & $\begin{array}{c}\text { Resistente, compacta e prováveis } \\
\text { nódulos de carbonato de cálcio }\end{array}$ \\
\hline A02 & Castanho claro & 2,5 & $\begin{array}{c}\text { Pouco resistente, quebradiça e provável } \\
\text { carbonato de cálcio }\end{array}$ \\
\hline A03 & Clara & 2,7 & $\begin{array}{c}\text { Pouco resistente e prováveis pequenos } \\
\text { nódulos de carbonato de cálcio }\end{array}$ \\
\hline A04 & Clara & 3,2 & $\begin{array}{c}\text { Resistente, compacta e prováveis } \\
\text { pequenos nódulos de carbonato de cálcio }\end{array}$ \\
\hline A06 & Clara & 3,7 & $\begin{array}{c}\text { Pouco resistente e prováveis pequenos } \\
\text { nódulos de carbonato de cálcio }\end{array}$ \\
\hline
\end{tabular}

\section{Análise termogravimétrica}

A análise termogravimétrica (TG/DTG) permitiu identificar as perdas de massa e os picos endotérmicos das amostras de argamassas analisadas.

A partir dos dados obtidos de cada TG, foi feita uma análise aplicando o padrão convencional de faixas de temperatura relatado na literatura por Bakolas et al. (1995a, 1995b, 1998), Moropoulou, Bakolas e Bisbikou (1995) e Moropoulou, Bakolas e Bisbikou (2000), Maravelaki-Kalaitzaki, Bakolas e Moropoulou (2003), Ingo et al. (2004) e Genestar, Pons e Más (2006).

As Figuras 14 a 16 ilustram as curvas TG e dTG de cada amostra de argamassa.

Diante o resultado de análise termogravimétrica de todas as argamassas, foi possível detectar três picos com suas perdas de massa para todas as amostras. $\mathrm{O}$ primeiro pico no intervalo de $50{ }^{\circ} \mathrm{C}$ a $120^{\circ} \mathrm{C}$ indica perda de massa pertinente à água fisicamente adsorvida ao material. No intervalo de $350{ }^{\circ} \mathrm{C}$ a $550{ }^{\circ} \mathrm{C}$ aparece outro pico, que está relacionado à desidratação de argila ou de alguns argilominerais, como a caulinita, oriundos de impurezas presente na areia ou na cal utilizada na argamassa. E a partir de $600{ }^{\circ} \mathrm{C}$ são os picos relacionados à presença de carbonatos, ou seja, quando acontece a decomposição de carbonato de cálcio $\left(\mathrm{CaCO}_{3}\right)$, como a calcita.

O termograma das argamassas (A01, A03, A04, A05 e A06) apresentou resultados semelhantes, corroborando com o FRX e DRX destas. Foi possível observar um pico de pequena intensidade que indica uma perda em pequena quantidade de massa, entre $350{ }^{\circ} \mathrm{C}$ e $550{ }^{\circ} \mathrm{C}$, representando a desidratação de argilominerais, do tipo caulinita, e um pico de alta intensidade, no intervalo de $730{ }^{\circ} \mathrm{C}$ a $750{ }^{\circ} \mathrm{C}$, que indica a perda de dióxido de carbono em decorrência da decomposição de $\mathrm{CaCO}_{3}$, do tipo calcita, como observado nos resultados de DRX dessas amostras, eventos térmicos também identificados por Damas et al. (2018) e Sousa (2014) em suas pesquisas. Damas et al. (2018) explicam ainda que a presença de minerais argilosos pode ser justificada pelo uso de areias não lavadas.

O termograma da argamassa A02 se diferenciou dos demais, apresentando resultado condizente com o que já foi observado em seu resultado de DRX e FRX. Foi possível identificar em sua análise termogravimétrica um pico de alta intensidade, quando comparado com as demais argamassas, no intervalo de $350{ }^{\circ} \mathrm{C}$ a $550{ }^{\circ} \mathrm{C}$, que representa a desidratação em grande quantidade de argila, do tipo ferro, ratificando, portanto, a presença desse material na amostra. Esse é um dos argilominerais presente na composição da argila, e que aparece em forma de hematita somente nessa amostra. Observou-se ainda, um pico de intensidade semelhante, em 750

${ }^{\circ} \mathrm{C}$, que indica a perda de dióxido de carbono devido a decomposição de $\mathrm{CaCO}_{3}$, do tipo calcita, como observado nos resultados de DRX dessa amostra.

Perante os resultados vistos de TG/dTG, as argamassas A01, A03, A04, A05 e A06 podem se classificar em argamassas de cal e areia, e a A02 em argamassas de cal, areia e argila, conforme Damas et al. (2018), Botas, Veiga e Velosa (2017), Sousa (2014) e Veiga (2006) citam em suas pesquisas. 
Figura 14 - (a) TG/dTG das amostras de argamassa de revestimento externo - A01 (a) e interno - A02 (b) do prédio administrativo

A01

A02
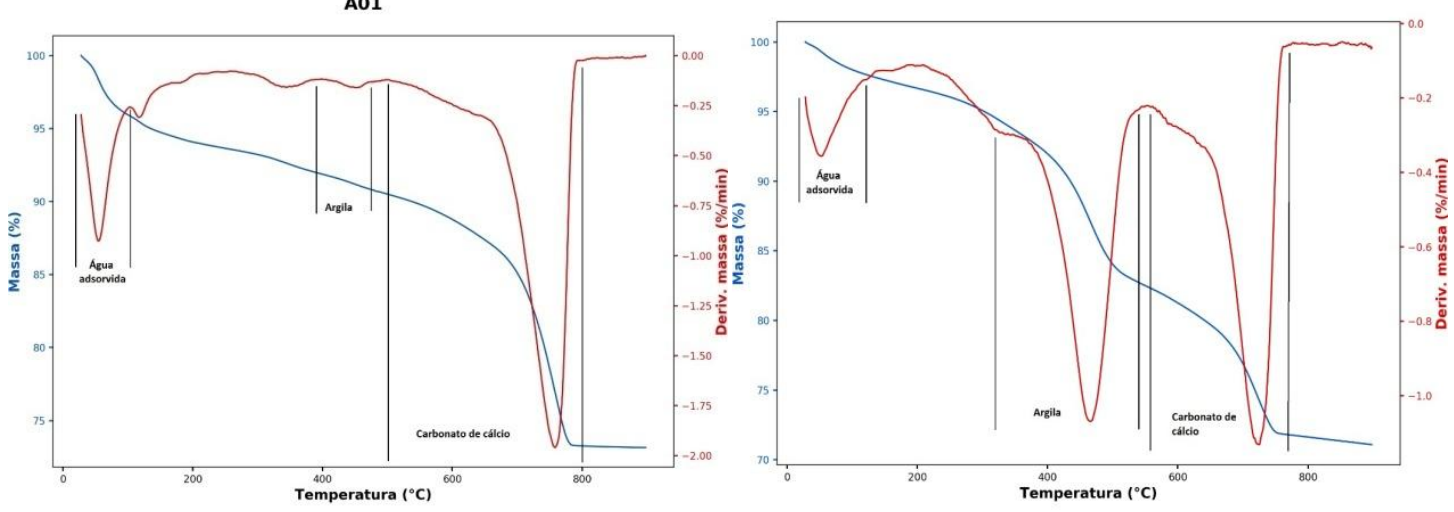

— Massa (\%) — Deriv. massa (\%/min)

— Massa (\%) — Deriv. massa (\%/min)

Figura 15 - (a) TG/dTG das amostras de argamassa de revestimento externo - A03 (a) e interno - A04 (b) da balança

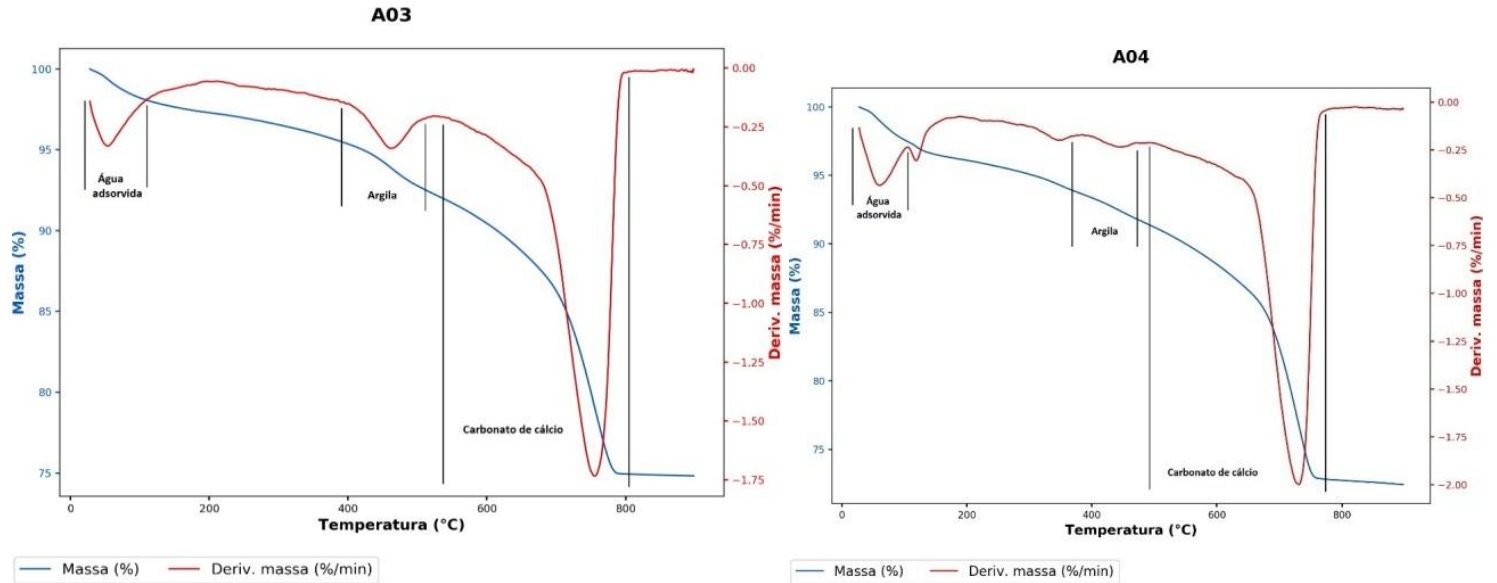

Figura 16 - (a) TG/dTG das amostras de argamassa de revestimento externo - A05 (a) e interno - A06 (b) da fábrica
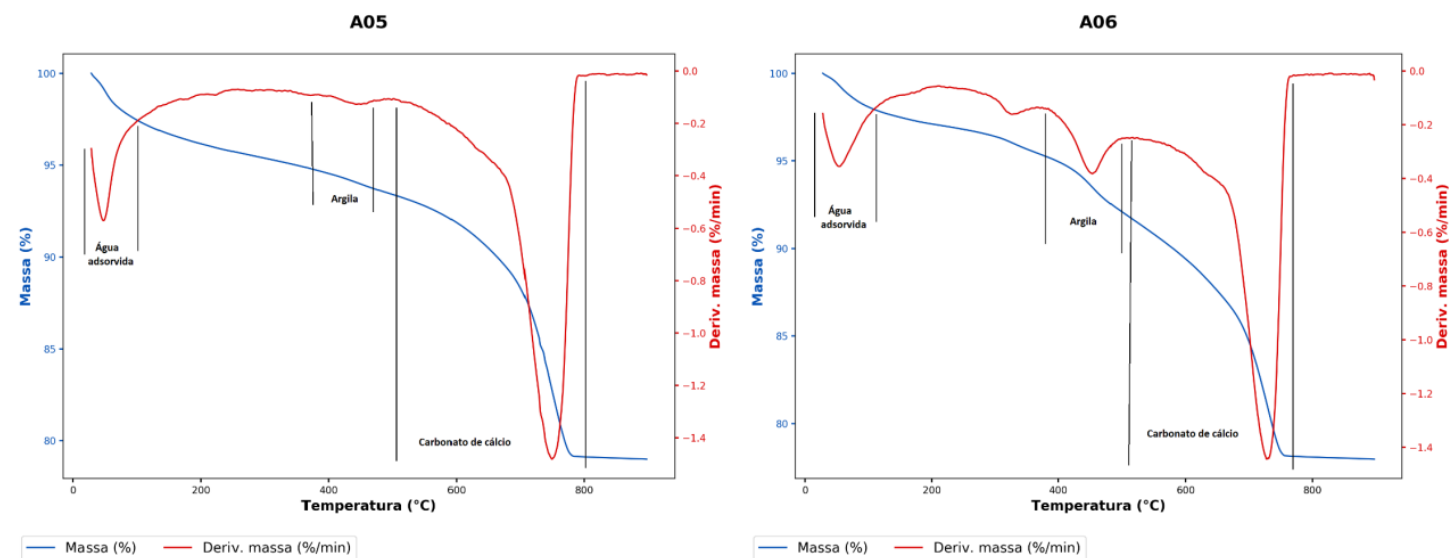

— Massa (\%) — Deriv. massa (\%/min)

A partir das porcentagens de perda de carbonato de cálcio observadas em cada amostra pelo termograma, calculou-se a porcentagem de agregado e, desse modo, foi possível estimar o teor aglomerante/agregado em massa, como mostra a Tabela 5. 
Tabela 5 - Estimativa de porcentagem do teor de aglomerante e agregado e traço das argamassas pelo resultado da $\mathrm{TG} / \mathrm{dTG}$

\begin{tabular}{c|c|c|c}
\hline Amostra & \% CaCO $_{\mathbf{3}}$ & \%Agregado & Aglomerante:agregado (g) \\
\hline A01 & $18 \%$ & $82 \%$ & $1: 5$ \\
A02 & $10 \%$ & $90 \%$ & $1: 9$ \\
A03 & $15 \%$ & $85 \%$ & $1: 6$ \\
A04 & $18 \%$ & $82 \%$ & $1: 5$ \\
A05 & $14 \%$ & $86 \%$ & $1: 6$ \\
A06 & $14 \%$ & $86 \%$ & $1: 6$ \\
\hline
\end{tabular}

Observa-se que o traço das amostras (A01, A03, A04, A05 e A06) apresentou valores mais próximos, assim como nos demais resultados anteriores, confirmando a semelhança entre essas amostras, sendo as amostras A01 e A04 com o traço de 1:4 e as amostras A03, A05 a A06 com traço de 1:6, enquanto a amostra A02 apresentou o valor de traço mais distante, de 1:9, confirmando mais uma vez a diferença dessa amostra quando comparada às demais.

\section{Teor de aglomerante e agregado}

Por meio da adaptação de tratamento térmico com dissolução em ácido clorídrico, foi permissível a obtenção da porcentagem de aglomerante de cada amostra e, por conseguinte, conceber outra estimativa de teor aglomerante/agregado (traço).

A Tabela 6 apresenta a relação aglomerante/agregado em massa, encontrados pela técnica do ataque ácido, a partir do teor de aglomerante e de agregado.

Esses dados reafirmam a similaridade entre as argamassas analisadas, como já relatado anteriormente, excetuando-se a amostra A03, que apresentou maior divergência, correlacionando este com os seus resultados anteriores.

As amostras A01 e A04 apresentaram um teor de aglomerante:agregado de 1:3 e 1:4, respectivamente, cujos traços são mais resistentes, atestando o aspecto resistente e compacto, quando da observação visual dessas argamassas. A amostra A03 apresentou um traço em peso de 1:8, valor mais alto comparado ao traço obtido pela TG, mas que certifica a análise visual dessa amostra, que indica um aspecto pouco resistente. A amostra A02 apresentou semelhança com a A03, com traço também de 1:8, confirmando a observação visual dessa argamassa, que exibe um aspecto pouco resistente e quebradiço. E as amostras A05 e A06 apresentaram teor de aglomerante:agregado de aproximadamente 1:6 e 1:7, conferindo um traço menos resistente que as amostras A01 e A04 e, consequentemente, um aspecto menos resistente dessas argamassas, como observado na análise visual.

A Tabela 7 mostra a relação aglomerante/agregado encontrado para as argamassas da Usina pelos dois métodos.

Portanto, da análise desses valores em termos de traço obtidos pela TG para o prédio administrativo tem-se para o revestimento externo o traço 1:5 e para o revestimento interno o traço 1:9. Para a balança, o traço 1:6 para o revestimento externo e 1:5 para o revestimento interno. E para a fábrica, o traço 1:6 tanto para o revestimento externo como para o revestimento interno.

E da análise dos traços obtidos pelo método do ataque ácido, tem-se para o prédio administrativo o traço 1:3 para o revestimento externo e 1:8 para o revestimento interno. Para o prédio da balança, o traço 1:8 para o revestimento externo e 1:4 para o revestimento interno. E para a fábrica, o traço 1:6 para o revestimento externo e 1:7 para o revestimento interno.

Considera-se, assim, três tipos de argamassa na Usina, em que a composição de aglomerante e agregado é semelhante, que são o traço (1:4) para as amostras A01 e A04, outro (1:9) para a amostra A02 e um terceiro traço (1:6) para as amostras A03, A05 e A06.

\section{Análise granulométrica}

O ensaio de granulometria do agregado presente nas amostras da camada de revestimento da argamassa antiga da Usina foi realizado a partir da amostra obtida após o ensaio de determinação do teor de aglomerante por ataque ácido. 
Tabela 6 - Estimativa da massa (g) do agregado e aglomerante e do traço das argamassas

\begin{tabular}{c|c|c|c|c}
\hline Amostra & Aglomerante (g) & Agregado (g) & $\begin{array}{c}\text { Aglomerante: } \\
\text { agregado }\end{array}$ & $\begin{array}{c}\text { Aglomerante:Agregado } \\
\text { equivalentes }\end{array}$ \\
\hline A01 & 12,433 & 37,000 & $1: 3,3$ & $1: 3$ \\
A02 & 5,367 & 44,433 & $1: 8,2$ & $1: 8$ \\
A03 & 5,467 & 44,367 & $1: 8,1$ & $1: 8$ \\
A04 & 10,000 & 39,333 & $1: 3,9$ & $1: 4$ \\
A05 & 6,933 & 42,633 & $1: 6,1$ & $1: 6$ \\
A06 & 6,033 & 43,833 & $1: 7,2$ & $1: 7$ \\
\hline
\end{tabular}

Tabela 7 - Relação aglomerante:agregado das argamassas pelos métodos TG e ataque ácido

\begin{tabular}{c|c|c}
\hline \multirow{2}{*}{ Amostra } & \multicolumn{2}{|c}{ Aglomerante:agregado } \\
\cline { 2 - 3 } & TG & Ataque ácido \\
\hline A01 & $1: 5$ & $1: 3$ \\
A02 & $1: 9$ & $1: 8$ \\
A03 & $1: 6$ & $1: 8$ \\
A04 & $1: 5$ & $1: 4$ \\
A05 & $1: 6$ & $1: 6$ \\
A06 & $1: 6$ & $1: 7$ \\
\hline
\end{tabular}

Observou-se que o agregado silicioso, a areia, possui maior quantidade de grãos de 0,15 mm a 0,075 mm de diâmetro, chegando a mais de $80 \%$, indicando, dessa forma, que o agregado mais presente na composição da areia da argamassa da Usina é um agregado fino. A Figura 17 ilustra as curvas granulométricas de cada amostra de argamassa da Usina e também as curvas que indicam as zonas utilizável e ótima dos limites inferior e superior do agregado.

Nota-se que as curvas granulométricas são praticamente paralelas, ou seja, apresentam aproximadamente a mesma distribuição de grãos e exibem característica de distribuição de grão predominante contínua.

Para classificação dos agregados siliciosos, de acordo com a NBR 7211 (ABNT, 2009), foram calculadas as propriedades físicas a partir da análise das curvas granulométricas (Figura 17), que estão indicadas na Tabela 8.

Como pode ser aferido na Tabela 8, o diâmetro máximo $(\mathrm{mm})$ para todas as amostras de argamassa é o mesmo, 2,36 mm, exceto para a amostra A01, que apresentou um diâmetro máximo menor, de $1,18 \mathrm{~mm}$. Esse diâmetro máximo significa a dimensão máxima que essa amostra de agregado possui, ou seja, a A01 possui grãos com diâmetros menores comparado às demais amostras.

De acordo com os dados apresentados na Tabela 10 e Figura 17, o valor do Mf apresentou uma variação entre as amostras das argamassas, verificando-se que as amostras A02, A03 e A06 encontram-se na zona aceitável de utilização e são classificadas como areia fina, e as outras amostras, A01, A04 e A05, encontramse fora da zona utilizável inferior, classificando-se como areia muito fina, pois apresentaram Mf mais baixos, o que representa um solo mais fino.

Portanto, da análise desses valores em relação ao agregado, pode-se concluir que em todas as amostras coletadas há presença de uma quantidade predominante de agregado miúdo classificado como areia de quartzo fina ou muito fina, de acordo com o módulo de finura obtido e os resultados de FRX e DRX.

\section{Absorção de água por imersão}

A absorção de água por imersão é uma propriedade que indica o volume de poros permeáveis de um corpo sólido poroso. A Figura 18 ilustra a absorção de todas as amostras.

Pode-se considerar, diante da análise dos dados, que as amostras A01 e A04 são as argamassas que apresentaram menor valor de absorção de água por imersão, o que indica que essas argamassas possuem menor volume de poros permeáveis, condizente com seus resultados anteriores de relação aglomerante:agregado, que mostraram que essas argamassas possuem traço mais rico em ligante, e, de acordo com Ortega et al. (2018), o aumento do teor de cal no traço de uma argamassa proporciona uma redução de poros nesta. Silva, Pinto e Gomes (2014) ratificam ainda que o aumento de teor de ligante na 
quantidade de mistura de cal hidráulica natural implicará diminuição da porosidade e absorção de água da argamassa.

A amostra A01 pertencente ao revestimento externo do prédio administrativo da Usina foi a que apresentou a menor absorção de água, o que pode ser explicado pelo traço dessa amostra, que é o mais abundante em cal, e, ainda, pelo módulo de finura, pois é a argamassa que tem um agregado com menor módulo, o que demostra o emprego de areia mais fina nessa argamassa, e, de acordo com Cavaco (2005), isso colabora para que haja redução da porosidade e da absorção de água da argamassa.

Figura 17 - Curvas granulométricas da areia de todas as amostras da Usina e as curvas de zona utilizável e ótima de limite inferior e superior do agregado
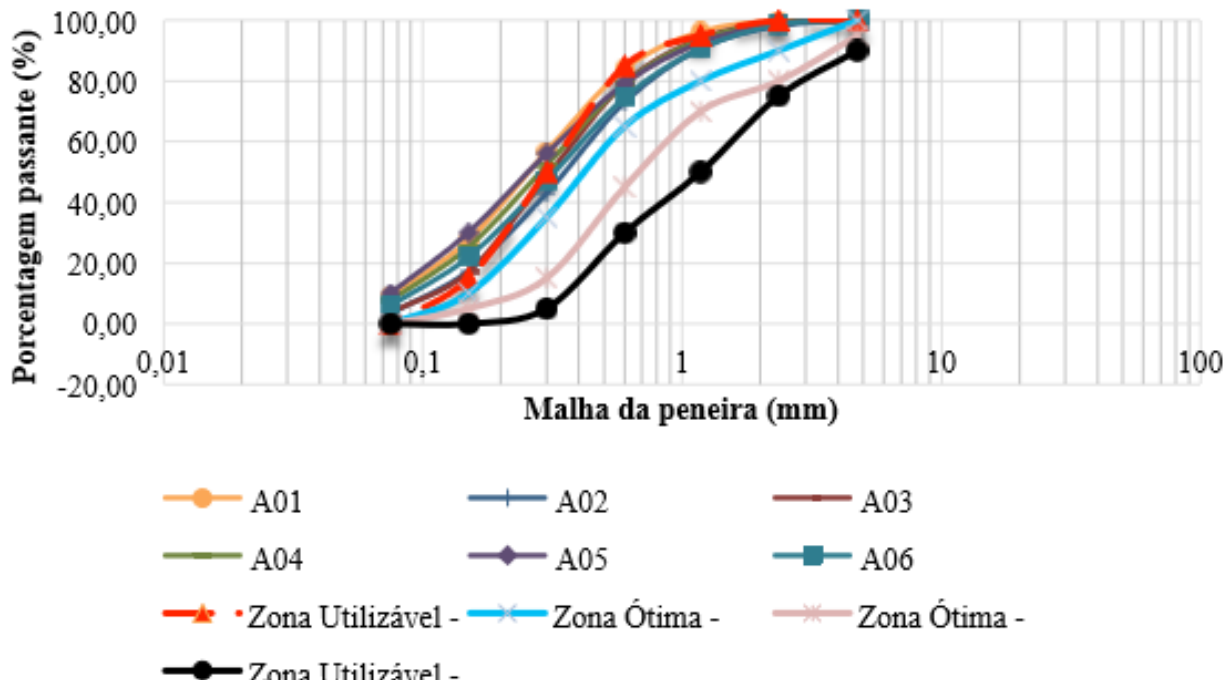

Tabela 8 - Propriedades físicas do agregado

\begin{tabular}{c|c|c|c|c|c|c}
\hline \multirow{2}{*}{ Propriedades físicas } & \multicolumn{7}{c}{ Agregado miúdo } \\
\cline { 2 - 7 } & $\mathbf{A 0 1}$ & $\mathbf{A 0 2}$ & $\mathbf{A 0 3}$ & $\mathbf{A 0 4}$ & $\mathbf{A 0 5}$ & $\mathbf{A 0 6}$ \\
\hline Diâmetro máximo (mm) & $1,18 \mathrm{~mm}$ & $2,36 \mathrm{~mm}$ & $2,36 \mathrm{~mm}$ & $2,36 \mathrm{~mm}$ & $2,36 \mathrm{~mm}$ & $2,36 \mathrm{~mm}$ \\
\hline Módulo de finura & 1,36 & 1,78 & 1,62 & 1,51 & 1,43 & 1,67 \\
\hline
\end{tabular}

Figura 18 - Absorção de água das amostras de argamassas da Usina

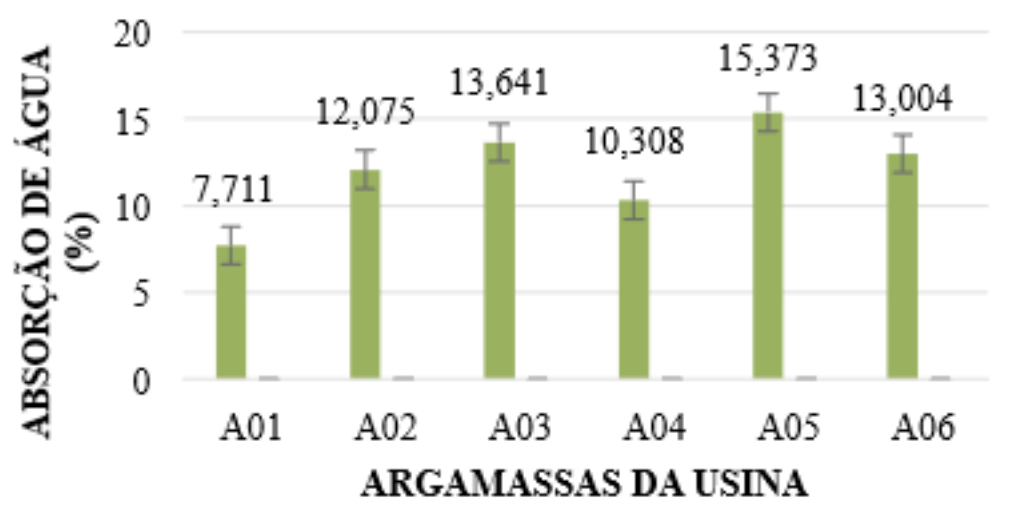




\section{Resistência à compressão}

A Figura 19 apresenta os valores de resistência à compressão para todas as argamassas da Usina.

De acordo com a Figura 19, é possível identificar que as amostras que apresentaram maiores resistências (A01 e A04) são justamente as argamassas que apresentaram aspecto resistente quando na observação visual e são as argamassas com traço mais rico em ligante, ratificando resultados anteriores. E dentre as seis amostras, a que se destaca é a argamassa A01, por alcançar melhor resistência mecânica, que pode ser justificada pelo traço mais forte em ligante, e o menor valor em módulo de finura e diâmetro máximo do agregado, pois, de acordo com Lanas et al., (2004), agregados com tamanho de grão pequeno demostram boa coesão na interface, o que melhora a resistência, e o aumento de ligante em um traço de argamassa confere a essa argamassa maior resistência mecânica, o que também é reportado por Damas et al. (2018), Sala et al. (2016) e Penas (2008).

A relação entre a resistência à compressão e a absorção de água por imersão das amostras é representada na Figura 20.

Comparando a resistência mecânica e absorção de água por imersão, é possível verificar que as argamassas que apresentaram menores valores de absorção de água foram exatamente as que alcançaram maior valor de resistência, e isso é mencionado na literatura. Segundo Silva, Pinto e Gomes (2014), a porosidade e a absorção de água da argamassa são diminuídas, enquanto exibem maior resistência mecânica precoce.

Figura 19 - Resistência à compressão das amostras de argamassas da Usina

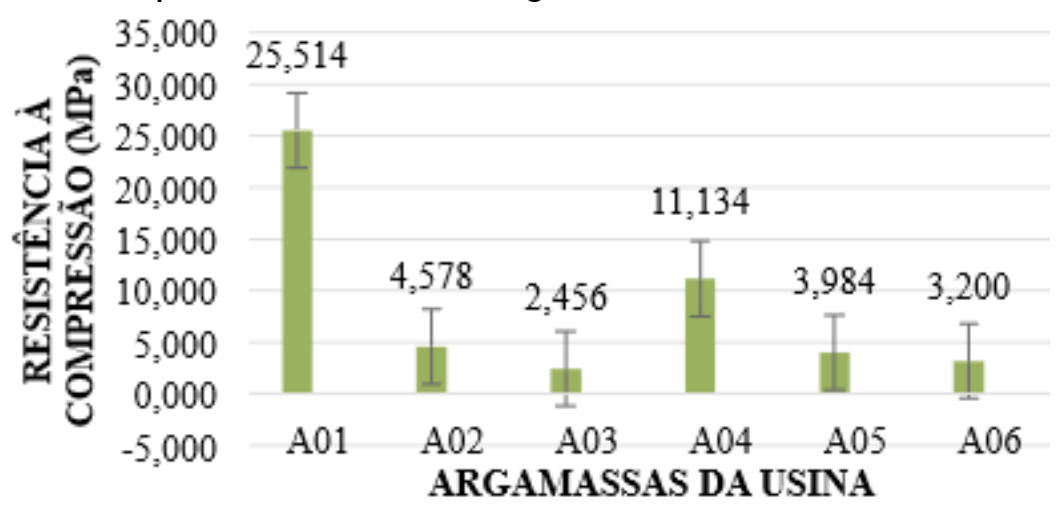

Figura 20 - Resistência à compressão versus absorção de água por imersão das argamassas da Usina

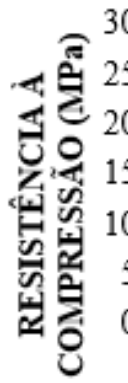

5
0
5
0
5
0

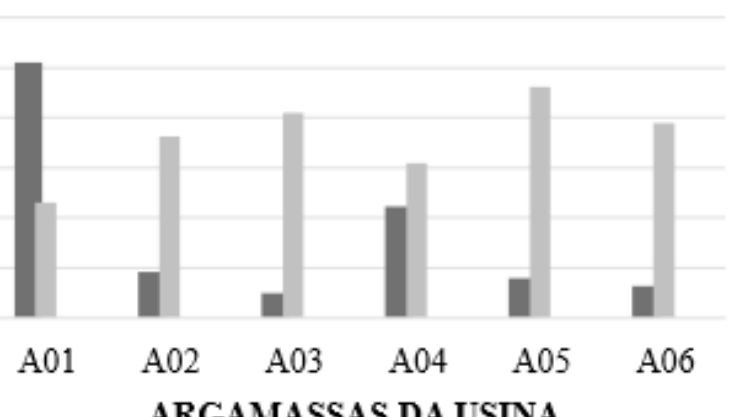

20

15

10

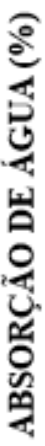

" RESISTÊNCIA À COMPRESSÃO " ABSORÇÃO DE ÁGUA 


\section{Conclusão/considerações finais}

A partir da análise dos resultados experimentais realizados no estudo de caracterização das argamassas de revestimento da Usina Ilha Bela, $\mathrm{RN}$, podem ser obtidas as seguintes conclusões:

(a) verificou-se que as argamassas coletadas são ricas em cal, com aglomerante de origem calcítica e areia de origem silicosa, como agregado;

(b) além dos principais constituintes, a cal e a areia, as amostras A01, A03, A04, A05 e A06 apresentaram anortita e caulinita, com exceção da A06. A caulinita indica a presença de argila na argamassa. E a anortita pode ser explicada devido à presença de cálcio e magnésio nas amostras. Enquanto a amostra A02 não apresentou caulinita e anortita, e, sim, hematita, o que explica a alta quantidade de ferro nessa amostra, corroborando com a sua coloração escura;

(c) todas as amostras extraídas da Usina apresentam possíveis nódulos de carbonato de cálcio e a maior parte apresenta uma cor clara, com exceção da A02, que tem uma tonalidade castanho claro devido à diferença em sua composição química, comparada às demais. Apresentam semelhança as amostras A01 e A04 na cor e são compactas e resistentes, divergindo na espessura; as amostras A02 e A03 na espessura e no aspecto pouco resistente; e as amostras A05 e A06 na cor, na espessura e no aspecto pouco resistente;

(d) as argamassas A01, A03, A04, A05 e A06 são constituídas de cal e areia, enquanto a argamassa A02 é constituída de cal, areia e argila;

(e) pode-se considerar que existem três tipos de argamassa na Usina, cujas relações aglomerante:agregado são: 1:4 para as amostras A01 e A04, 1:9 para a amostra A02 e 1:6 para as amostras A03, A05 e A06;

(f) o agregado miúdo, areia de quartzo, para as amostras A02, A03 e A06 encontra-se na zona aceitável de utilização e, por isso, é classificado como areia fina, e nas amostras A01, A04 e A05 encontra-se fora da zona utilizável inferior, classificando-se como areia muito fina; e

(g) as amostras A01 e A04 apresentaram menor valor de absorção de água por imersão, combinando com os resultados anteriores, pois estas possuem traço mais rico em ligante, e, segundo a literatura, quanto maior a quantidade de teor de cal no traço de uma argamassa, menor a absorção de água desta, combinando também com o resultado de resistência à compressão.

Portanto, no que se refere à conservação e futura consolidação desse patrimônio histórico, pode-se concluir como uma argamassa compatível à argamassa antiga da Usina Ilha Bela uma argamassa constituída de cal e areia, na proporção em massa aglomerante:agregado 1:4, com adequada resistência à compressão (de preferência com resistência menor que a verificada, evitando gerar tensões) e pouca absorção de água para as argamassas de revestimento externo do prédio administrativo e revestimento interno da balança; uma argamassa de reparo constituída de cal e areia com traço 1:9, com uma maior absorção de água e apresentando uma menor resistência à compressão, para as argamassas de revestimento interno do prédio administrativo, sendo esta constituída da argila como agregado, além da areia; e uma argamassa de restauro constituída de cal e areia, na proporção de 1:6, apresentando uma resistência à compressão um pouco menor, para as argamassas de revestimento externo da balança e da fábrica.

Logo, conhecidas as características das argamassas existentes da Usina Ilha Bela, fica como sugestão para trabalhos futuros o desenvolvimento de uma argamassa compatível para execução de uma intervenção de conservação e manutenção adequada desse patrimônio histórico.

\section{Referências}

ARAÚJO, R. A. Influência da utilização de resíduo de cerâmica vermelha nas propriedades de argamassas mistas. Natal, 2017. 95 f. Dissertação (mestrado) - Programa de Pós-Graduação em Engenharia Civil, Universidade Federal do Rio Grande do Norte, Natal, 2017.

ASSOCIAÇÃO BRASILEIRA DE NORMAS TÉCNICAS. NBR 5739: concreto: ensaio de compressão de corpos de prova cilíndricos. Rio de Janeiro, 2007.

ASSOCIAÇÃO BRASILEIRA DE NORMAS TÉCNICAS. NBR 7211: agregados para concreto: especificação. Rio de Janeiro, 2009.

ASSOCIAÇÃO BRASILEIRA DE NORMAS TÉCNICAS. NBR 9778: agregados: argamassa e concreto endurecidos: determinação da absorção de água por imersão: índice de vazios e massa específica. Rio de Janeiro, 2005. 
ASSOCIAÇÃO BRASILEIRA DE NORMAS TÉCNICAS. NBR NM 248: agregados: determinação da composição granulométrica. Rio de Janeiro, 2003.

BAKOLAS, A. et al. Characterization of structural byzantine mortars by thermogravimetric analysis.

Thermochimica Acta, v. 321, p. 151-160, nov. 1998.

BAKOLAS, A. et al. Characterization of the lumps in the mortars of historic masonry. Thermochimica Acta, v. 269/270, p. 809-816, dez. 1995a.

BAKOLAS, A. et al. Thermoanalytical research on traditional mortars in Venice. Thermochimica Acta, v. 269/270, p. 817-828, dez. 1995 b.

BARTZ, W. et al. Characterization of historical lime plasters by combined non-destructive and destructive tests: The case of the sgraffito in Bożnów (SW Poland). Construction and Building Materials, v. 30, p. 439-446, may 2012.

BERTRAND, D. Patrimônio, Memória e Espaço: a construção da paisagem açucareira do Vale do CearáMirim. Natal, 2010. 132 f. Dissertação (Mestrado em História) - Programa de Pós-Graduação em História, Centro de Ciências Humanas, Letras e Artes, Universidade Federal do Rio Grande do Norte, Natal, 2010.

BOTAS, S.; VEIGA, R.; VELOSA, A. Air lime mortars for conservation of historic tiles: bond strength of new mortars to old tiles. Construction and Building Materials, v. 145, p. 426-434, ago. 2017.

CAVACO, L. S. R. G. Técnicas de aplicação de argamassas de revestimento em edifícios antigos: Influência no desempenho. Lisboa, 2005. Dissertação (Mestrado em Engenharia Civil) - Instituto Superior Técnico de Lisboa, Lisboa, 2005.

DAMAS, A. L. et al. Characterisation of old azulejos setting mortars: a contribution to the conservation of this type of coatings. Construction and Building Materials, v. 171, p. 128-139, may 2018.

DAMAS, A. L.; VEIGA, M. R.; FARIA, P. Caraterização de argamassas antigas de Portugal: contributo para a sua correta conservação. In: CONGRESSO IBERO-AMERICANO "PATRIMÓNIO, SUAS MATÉRIAS E IMATÉRIAS”, Lisboa, 2016. Anais [...] Lisboa, 2016.

FARIA, P.; HENRIQUES, F.; RATO, V. Comparative evaluation of lime mortars for architectural conservation. Journal of Cultural Heritage, v. 9, p. 338-346, 2008.

GENESTAR, C.; PONS, C.; MÁS, A. Analytical characterisation of ancient mortars from the archaeological Roman city of Pollentia (Balearic Islands, Spain). Analytica Chimica Acta, v. 557, p. 373-379, 2006.

GLEIZE, P. J. P. et al. Characterization of historical mortars from Santa Catarina (Brazil). Cement and Concrete Composites, v. 31, p.342-346, may 2009.

HORMES, J. et al. The characterization of historic mortars: a comparison between powder diffraction and synchrotron radiation based X-ray absorption and X-ray fluorescence spectroscopy. Microchemical Journal, v. 125, p. 190-195, mar. 2016.

INGO, G. M. et al. Thermal and microchemical investigation of Phoenician-Punic mortars used for lining cisterns at Tharros (western Sardinia, Italy). Thermochimica Acta, v. 418, p. 53- 60, 2004.

INSTITUTO DO PATRIMÔNIO HISTÓRICO E ARTÍSTICO NACIONAL. O Iphan. Disponível em: http://portal.iphan.gov.br/. Acesso em: 30 out. 2017.

KANAN, M. I. C. Manual de Conservação e Intervenção em Argamassas e Revestimentos a Base de Cal. Cadernos Técnicos. Brasília, 2008. v. 8. IPHAN/Programa Monumenta.

LANAS, J. et al. Mechanical properties of natural hydraulic lime-based mortars. Cement and Concrete Research, v. 34, p. 2191-2201, dez. 2004.

LAVAT, A. E.; TREZZA, M. A.; POGGI, M. Characterization of ceramic roof tile wastes as pozzolanic admixture. Waste Management, v. 29, n. 5, p. 1666-1674, may 2009.

LEZZERINI, M. et al. Archaeometric study of mortars from the Pisa's Cathedral Square (Italy). Measurement, v. 126, p. 322-331, out. 2018.

LEZZERINI, M. et al. Characterization of historical mortars from the bell tower of St. Nicholas church (Pisa, Italy). Construction and Building Materials, v. 69, p. 203-212, out. 2014. 
MARAVELAKI-KALAITZAKI P. et al. Hydraulic lime mortars for the restoration of historic masonry in Crete. Cement and Concrete Research, v. 35, n. 8, p. 1577-1586, 2005.

MARAVELAKI-KALAITZAKI, P.; BAKOLAS, A.; MOROPOULOU, A. Physico-chemical study of cretan ancient mortars. Cement and Concrete Research, v. 33, p. 651-661, may 2003.

MOROPOULOU, A.; BAKOLAS, A.; ANAGNOSTOPOULOU, S. Composite materials in ancient structures. Cement and Concrete Composites, v. 27, p. 295-300, 2005.

MOROPOULOU, A.; BAKOLAS, A.; BISBIKOU, K. Characterization of ancient, byzantine and later historic mortars by thermal and X-ray diffraction techniques. Thermochimica Acta, v. 269-270, p. 779795, dez. 1995.

MOROPOULOU, A.; BAKOLAS, A.; BISBIKOU, K. Investigation of the technology of historic mortars. Journal Cultural Heritage, v. 1, p. 45-58, 2000.

MOTTA, E. V. Caracterização de argamassas de edificações históricas de Santa Catarina. Florianópolis, 2004. 114 f. Dissertação (Mestrado em Engenharia Civil) - Programa de Pós-Graduação em Engenharia Civil, Universidade Federal de Santa Catarina, Florianópolis, 2004.

ORTEGA, E. O. et al. Evolution of mechanical properties in aerial lime mortars of traditional manufacturing, the relationship between putty and powder lime. Construction and Building Materials, v. 191, p. 575-589, dez. 2018.

PENAS, F. E. Argamassas de cal hidráulica para revestimentos de paredes. Lisboa, 2008. $118 \mathrm{f}$. Dissertação (Mestrado em Engenharia Civil) - Instituto Superior Técnico, Universidade Técnica de Lisboa, Lisboa, 2008.

ROSA, P. J. P. Caracterização de argamassas históricas do Convento de Cristo - Tomar. Lisboa, 2016. 216 f. Dissertação (Mestrado em Engenharia Civil) - Programa de Pós-Graduação em Química, Universidade de Lisboa, Lisboa, 2016.

SALA, E. et al. Lightweight natural lime composites for rehabilitation of Historical Heritage. Construction and Building Materials, v. 125, p.81-93, out. 2016.

SILVA, B. A.; PINTO, A. P. F.; GOMES, A. Influence of natural hydraulic lime content on the properties of aerial lime-based mortars. Construction and Building Materials, v. 72, p. 208-218, dez. 2014.

SOUSA, A. K. D. Argamassas do grupo escolar Augusto Severo/RN: caracterização e incidência de manifestações patológicas. Natal, 2014. 140 f. Dissertação (Mestrado em Engenharia Civil) - Programa de Pós-Graduação em Engenharia Civil, Universidade Federal do Rio Grande do Norte, Natal, 2014.

TAGLIERI, G. et al. Eco-compatible protective treatments on an Italian historic mortar (XIV century). Journal of Cultural Heritage, v. 25, p. 135-141, may 2017.

TAVARES, M. L. A Conservação e o restauro de revestimentos exteriores de edifícios antigos: uma metodologia de estudo e reparação. Lisboa, 2009. 477 f. Tese (Doutorado em Engenharia Civil) - Programa de Pós-Graduação em Engenharia Civil, Universidade Técnica de Lisboa, Lisboa, 2009.

VEIGA, M. R. Air lime mortars: what else do we need to know to apply them in conservation and rehabilitation interventions? A review. Construction and Building Materials, v. 157, p. 132-140, 2017.

VEIGA, M. R. Argamassas de alvenarias históricas: funções e características. In: CONFERÊNCIA INTERNACIONAL SOBRE REABILITAÇÃO DE ESTRUTURAS ANTIGAS E ALVENARIA, Lisboa, 2012. Anais [...] Lisboa: Universidade de Lisboa, 2012.

VEIGA, M. R. Os revestimentos antigos e a identidade dos edifícios. Arquitectura Ibérica. Reabilitação, v. 12, p. 36-45, 2006.

VEIGA, M. R.; VElOSA, A. L. A cor das argamassas. Revista Construção Magazine, maio 2008.

YASEEN, I. A. B. et al. Petrography and mineralogy of Roman mortars from buildings of the ancient city of Jerash, Jordan. Construction and Building Materials, v. 38, p. 465-471, jan. 2013. 


\section{Adna Lúcia Rodruges de Menezes}

Programa de Pós-Graduação em Engenharia Civil | Universidade Federal do Rio Grande do Norte | Av. Sen. Salgado Filho, 3000 , Candelária | Natal - RN - Brasil | CEP 59064-741 | Tel.: (84) 99922-0343 | E-mail: adnalucia_@hotmail.com

\section{Kleber Cavalcanti Cabral}

Departamento de Engenharias | Universidade Federal Rural do Semi-Árido | Rua Gamaliel Martins Bezerra | Angicos - RN - Brasil | CEP 59515-000 | Programa de Pós-Graduação em Engenharia Civil | Universidade Federal do Rio Grande do Norte | Tel.: (84) 99984-1250 | Email: kleber.cabral@ufersa.edu.br

\section{Antonio Eduardo Martinelli}

Programa de Pós-Graduação em Ciência e Engenharia dos Materiais | Universidade Federal do Rio Grande do Norte | Tel.: (84) 99913-7474 | E-mail: martinelli.ufrn@gmail.com

\section{Ambiente Construído}

Revista da Associação Nacional de Tecnologia do Ambiente Construído Av. Osvaldo Aranha, $99-3^{\circ}$ andar, Centro

Porto Alegre - RS - Brasil

$$
\text { CEP } 90035-190
$$

Telefone: +55 (51) 3308-4084

Fax: +55 (51) 3308-4054

www.seer.ufrgs.br/ambienteconstruido

E-mail: ambienteconstruido@ufrgs.br

This is an open-access article distributed under the terms of the Creative Commons Attribution License. 